\title{
Rhubarb/Licorice Herbal Supplement
}

National Cancer Institute

\section{Source}

National Cancer Institute. Rhubarb/Licorice Herbal Supplement. NCI Thesaurus. Code C99635.

A decoction of rhubarb root (Da Huang) and licorice root (Gan Cao) used in Chinese Herbal Medicine. Upon ingestion, the rhubarb/licorice herbal supplement may help improve appetite. 